\author{
Maria Mocarz-Kleindienst \\ Katolicki Uniwersytet Lubelski Jana Pawła II
}

\title{
MIEJSCE PRZEKEADU FILMOWEGO W BADANIACH TRANSLATORYCZNYCH
}

\begin{abstract}
Zarys treści: Współczesna kultura audiowizualna przyczyniła się do znacznego wzrostu zainteresowania produkcją filmów oraz ich przekładami. Obok zainteresowań praktycznych coraz większą uwagę badacze skupiają na aspektach teoretycznych tego typu przekładu. W dotychczasowych koncepcjach typologii przekładu przekład filmowy często nie był uwzględniany lub traktowany marginalnie, jako zupełnie odrębny typ przekładu. Tymczasem masowy charakter odbioru treści audiowizualnych, różnorodność technik tłumaczeniowych wykorzystywanych w przekładzie filmowym skłaniają do dokładnej analizy miejsca przekładu filmowego w ogólnej typologii przekładu. W artykule zaprezentowano przegląd koncepcji typologii przekładu filmowego. Jednocześnie przedstawiono nową typologię, uwzględniającą rodzaj medium w przekazie informacji. Na podstawie tego kryterium wyróżniono następujące typy tekstów i jednocześnie przekładu: 1) wizualne (werbalne, ikoniczne, werbalno-ikoniczne) 2) audialne, 3) audiowizualne.
\end{abstract}

Słowa kluczowe: przekład audiowizualny; techniki tłumaczeniowe; typologie przekładowe

Yultura audiowizualna końca XX i początku XXI wieku przyczyniła się do Nznacznego wzrostu zainteresowania produkcją filmów, a także ich przekładami, będącymi niejednokrotnie nieodłącznym etapem mechanizmów dystrybucji takich produkcji. Przekład filmowy staje się istotnym medium komunikacji interkulturowej z uwagi na swój masowy, w znacznym stopniu oparty na wizualizacji charakter odbioru. Michał Garcarz słusznie postrzega film jako „generator informacji kulturowej” (Garcarz 2007: 21). Ogólną łatwą dostępność do produkcji audiowizualnych zapewniają nowoczesne technologie, które nieustannie proponują nowe, coraz bardziej udoskonalane formy kontaktu z kulturą audiowizualną (np. telewizja satelitarna, technologie interaktywne iTV). Zainteresowania praktyczne produkcją, dystrybucją i odbio- 
rem filmu sprawiły jednocześnie, że badacze coraz większą uwagę skupiają na aspektach teoretycznych tego typu przekładu. Zjawisko takie w sytuacji rosnącej popularności przekładu filmowego wydaje się ze wszech miar pożądane, pozwoli bowiem uporządkować m.in. system klasyfikacyjny. Dokonując przeglądu literatury przedmiotu poświęconej teoretycznym aspektom funkcjonowania przekładu filmowego, można zauważyć zainteresowania badaczy w kierunku analizy konkretnych technik tłumaczeń (dubbing, napisy, wersja lektorska) czy też prób porównania, wręcz wartościowania technik stosowanych przez tłumaczy filmowych (Bogucki 2004; Tomaszkiewicz 2006; Garcarz 2007; Szarkowska 2008 i in). W mniejszym stopniu natomiast uwaga badaczy skupia się na zagadnieniach samej typologii tłumaczeń filmowych, w szczególności w kontekście ogólnej typologii tłumaczeń. W dotychczasowych koncepcjach typologicznych przekład filmowy nie był uwzględniany lub był traktowany marginalnie, przez długi czas pokutowało przekonanie, że „tłumaczenie filmowe jest problemem peryferyjnym w teorii przekładu i niezbyt ważnym" (Withman-Linsen, cyt. za: Tomaszkiewicz 2006: 104). Wyraźnie preferowano przekład tekstów literackich jako bardziej wartościowych form komunikacji wewnątrz- i międzykulturowej (Szarkowska 2008: 8).

Status społeczny kina i telewizji w kulturze XX wieku, który odcisnął piętno również na zagadnieniach tłumaczeniowych, trafnie określa Maryla Hopfinger, formułując następującą myśl:

Historia wrastania kina w kulturę XX wieku pokazuje, że nie był to proces łatwy. Tradycja stawiała opór. Kino - najpierw dosyć prymitywne - uważane było za spektakularny przejaw barbarzyństwa. [...] Długo [...] walczyło kino o przyjęcie do panteonu sztuk i o awans kulturowy. Z akceptacją telewizji poszło już znacznie łatwiej, chociaż ona sama raczej nie miała artystycznych aspiracji (Hopfinger 1997: 56).

Tymczasem druga połowa XX wieku przyniosła wyraźną zmianę preferencji w zakresie form kontaktu z kulturą. Nastąpiło przesunięcie punktu ciężkości z zainteresowania literaturą, książką na zainteresowanie produkcjami filmowymi oraz technikami tłumaczeniowymi wykorzystywanymi w przekładzie filmowym (wersja lektorska, dubbing, napisy, audiodeskrypcja). Co więcej, Mary Snell-Hornby twierdzi, że film zrodziła właśnie literatura (Snell-Hornby 1988: 32), adaptacja dzieł literackich na potrzeby kina i telewizji. W konsekwencji tych zdarzeń teoretycy przekładu dostrzegli potrzebę podjęcia próby ustalenia typologii przekładu z uwzględnieniem w niej 
przekładu filmowego ${ }^{1}$. Stąd też celem niniejszego tekstu będzie prezentacja koncepcji typologii przekładu filmowego w kontekście istniejących ogólnych typologii, zmierzająca do ich modyfikacji (m.in. klasycznej typologii przekładu Romana Jakobsona). Ustalenie miejsca przekładu filmowego jak i audiowizualnego w ogóle w badaniach translatorycznych ma na celu uzyskanie przejrzystości typologicznej, ustalenie relacji pomiędzy przekładem filmowym a innymi typami tłumaczeń. Ale nie tylko. Lokalizacja takiego przekładu w ogólnym systemie w dalszej perspektywie badawczej pozwoli uzasadnić wybór strategii translatorskich i technik przekładu oraz wskazać na potrzebę weryfikacji istniejących technik, w większości zorientowanych do tej pory na przekłady tekstów werbalnych.

W pracach poświęconych zagadnieniom przekładu filmowego (i szerzej - audiowizualnego) dominuje następujące stwierdzenie: przekład filmowy jest odrębnym typem $\mathrm{z}$ uwagi na odrębność procesów $\mathrm{w}$ nim zachodzących (Goc 2013: 37; Pieńkos 2003). W dalszej części niniejszego opracowania postaram się tę tezę zweryfikować.

Przyglądając się uważniej owej odrębności, można moim zdaniem wskazać na kilka przesłanek zaistniałej sytuacji. Do najważniejszych należy zaliczyć:

I. Stałe współwystępowanie w przekazie audiowizualnym kilku kanałów (kodów) przekazu informacji. Badacze zajmujący się problematyką tłumaczeń audiowizualnych wyróżniają następujące typy:

1) kanał dźwiękowy werbalny - dialogi aktorów, piosenki, odgłosy w tle,

2) kanał dźwiękowy niewerbalny - muzyka, efekty dźwiękowe,

3) kanał wizualny werbalny - napisy, szyldy, gazety, dokumenty,

4) kanał wizualny niewerbalny - obrazy, sceny (Szarkowska 2008: 11).

Powyższe kanały podlegają odrębnym procesom tłumaczenia, w zależności od przyjętej techniki i potrzeb szczególnych grup odbiorców (m.in. z dysfunkcją wzroku lub słuchu) podlegają różnym konfiguracjom. Dla przykładu w audiodeskrypcji kod wizualny niewerbalny zostaje przekazany za pomocą kodu dźwiękowego werbalnego, z kolei w wersji dla niesłyszących spotykamy konfigurację odwróconą: system znaków w kodzie dźwiękowym

${ }^{1}$ Odrębny problem stanowi pytanie, na ile dotychczas wypracowanie założenia metodologiczne są wystarczające dla kompleksowej analizy materiałów tłumaczeń filmowych. Mam tu na myśli np. dostosowanie typologii transformacji tłumaczeniowych do potrzeb przekazu filmowego. Niektórzy badacze są skłonni reprezentować pogląd, że mimo odrębnego statusu tłumaczenia audiowizualnego (w tym filmowego) można wykorzystać istniejące propozycje metodologiczne, które dzięki swoim kompleksowym założeniom dadzą się dopasować do warunków przekładu filmowego. Taką możliwość zapewniają m.in. opisowe badania nad przekładem (Goc 2013: 37). 
werbalnym jak również niewerbalnym zostaje przekazany za pomocą kodu wizualnego werbalnego. Takie egzemplifikacje współwystępowania różnych kodów niewątpliwie utrudniają procedurę typologii z udziałem w niej przekładu filmowego.

II. Wyżej wymienione kanały powiązane są między sobą licznymi relacjiami intersemiotycznymi, m.in. komplementarności, paralelizmu, ekwiwalencji (Tomaszkiewicz 2006: 58 i in.), redundacji, uzupełniania (Ekman,Friesen 1969), a także fragmentaryczności, kondensacji i in., w różnym stopniu relewantnych dla poszczególnych technik tłumaczenia filmowego.

III. Szerokie możliwości rozwiązań technicznych w produkcji i zakresie dystrybucji treści programów audiowizualnych (filmowych w szczególności) pozwalają na niezależne wykorzystanie kilku technik tłumaczeniowych (dubbing, wersja lektorska, napisy), co niewątpliwie wpływa na złożony charakter takiego przekładu. W konsekwencji w ramach jednego typu przekładu uzyskujemy przekaz informacji w przekładzie na pomocą kanałów ustnych (dubbing, wersja lektorska) i pisemnych (napisy). Przekład filmowy łączy w sobie cechy typologii przekładu opartej na kanale przepływu informacji - wyróżniamy w nim techniki oparte na przekładzie ustnym jako finalnym efekcie usługi tłumaczenia oraz na przekładzie pisemnym, którym będą bez wątpienia napisy (w tym napisy dla niesłyszących).

Mimo tak zarysowanej złożoności zjawiska przekładu filmowego spróbujmy umiejscowić przekład filmowy w przestrzeni ogólnej typologii tłumaczeń. W tym miejscu wypada przytoczyć klasyczną typologię zaproponowaną w latach 50. przez Romana Jakobsona. Badacz ten wyróżnił następujące typy tłumaczeń:

- tłumaczenie intralingwalne - przekaz znaków językowych za pomocą innych znaków językowych dokonywany w obrębie tego samego języka,

- tłumaczenie interlingwalne - przekaz znaków językowych jednego języka za pomocą systemu znaków należących do innego języka (przekład właściwy),

- tłumaczenie intersemiotyczne (transmutacja) - interpretacja jednego systemu znaków za pomocą innego systemu znaków (np. znaków werbalnych na system znaków wizualnych).

Jak widać, autor przytoczonej koncepcji bazuje jednocześnie na dwóch kryteriach klasyfikacyjnych: zakresie oddziaływania systemów znaków językowych (wewnątrz jednego systemu lub poza nim z wykorzystaniem innego systemu, z wyjściem na inny system znaków) oraz typie znaków. Mając na uwadze drugie kryterium, Jakobson kieruje się podstawową dychotomią 
w tym zakresie - podziałem na znaki werbalne i pozawerbalne. Jednocześnie zauważmy, że wskazuje on na jednokierunkowy typ interpretacji, mianowicie mówi o interpretacji znaku werbalnego za pomocą systemu znaków niewerbalnych (np. przekazie słowa za pomocą obrazu). W rzeczywistości może to być interpretacja dwukierunkowa: zatem interpretacji mogą podlegać systemy znaków niewerbalnych za pomocą znaków werbalnych, czyli obraz przekazujemy przy użyciu słów. W obrębie tak rozumianego przekładu intersemiotycznego sytuuje się audiodeskrypcja, niekiedy również napisy dla niesłyszących. Jeśli przyjąć, że w obrębie różnych systemów znaków umiejscowione są wspomniane przez mnie wcześniej kody: wizualny i dźwiękowy, w ramach tłumaczenia intersemiotycznego możemy ulokować również napisy (podpisy) czy tzw. techniki poboczne (np. nadpisy stosowane w operach, musikalach) ${ }^{2}$.

Jeśli zatrzymać się przy pierwszym kryterium uwzględnionym przez Jakobsona, w ramach tłumaczenia intralingwalnego odnajdziemy również audiodeskrypcję, wersję dla niesłyszących - wobec braku zmiany kodu językowego. Przekład filmowy ze względu na wielokontekstowość jego zastosowania i różnorodność technik w nim stosowanych można usytuować wewnątrz tłumaczenia interlingwalnego, w sytuacji przekładu z jednego języka na inny. Wewnątrz tłumaczenia interlingwalnego umiejscowić możemy wersję lektorską oraz dubbing.

W ten sposób poszczególne techniki tłumaczenia filmowego stają się niejako egzemplifikacją odrębnych typów tłumaczenia wyróżnionych przez Jakobsona. Analizując tę typologię, Teresa Tomaszkiewicz postrzega przekład audiowizualny jako łączący w sobie elementy tłumaczenia interlingwalnego i tłumaczenia intersemiotycznego (Tomaszkiewicz 2006: 100). Takie przesłanki skłaniają do sformułowania wniosku, że przekład audiowizualny jest pojęciem krzyżującym się z typami tłumaczeń w klasycznej definicji Jakobsona, trudno natomiast ustalić przejrzyste relacje nadrzędności lub podrzędności tych pojęć. Zestawienie dwóch kryteriów jako podstawy klasyfikacji, o których była mowa powyżej, nie gwarantuje przejrzystości typologicznej w udziałem w niej tłumaczenia filmowego (audiowizualnego). Skumulowanie kilku kryteriów klasyfikacyjnych dostrzec można również w propozycji typologii przekładu Jerzego Pieńkosa, który przekład tekstów na potrzeby ki-

2 Teresa Tomaszkiewicz zwraca uwagę na jeszcze jeden interesujący fakt: otóż zauważa, że teoretycy kina jako tłumaczenie intersemiotyczne traktują również adaptacje dzieł literackich na dzieła filmowe (Tomaszkiewicz 2006: 76). Taki punkt widzenia prezentuje m.in. Maryla Hopfinger, podkreślając przy tym fakt nierówności przekładu intersemiotycznego spowodowany brakiem równoważności między systemami uczestniczącymi w takim przekładzie (Hopfinger 1974: 82). 
nematografii sytuuje obok przekładu literackiego, poetyckiego, symultanicznego, konsekutywnego, prawnego i prawniczego oraz innych. (Pieńkos 2003: 74-80 i in.).

Z kolei D. Gouadec, proponując własną kategoryzację tłumaczeń pisemnych, potraktował przekład audiowizualny wraz z przekładem filmowym jako szczególny typ tłumaczenia specjalistycznego wbudowanego w specyficzne media, wymagającego zastosowania specjalnych technologii multimedialnych. W kręgu takich tłumaczeń Gouadec usytuował lokalizację (np. programową) oraz interesujące nas w szczególności tłumaczenia medialne, w ramach których wyróżnia m.in. napisy filmowe, dubbing, narracje teatralne (Gouadec 2007).

Badacze niemieccy z kolei, wykorzystujący typologię tłumaczenia Kathariny Reiss, opartą na prymarnych funkcjach tekstu, postulują włączenie przekładu filmowego do tekstów z prymarną funkcją ekspresywną (jest to założenie oczywiście uzasadnione wyłącznie w przypadku filmów fabularnych). Z kolei Mary Snell-Hornby, nawiązując do klasyfikacji funkcjonalnej Kathariny Reiss, teksty audiomedialne (a zatem i tłumaczenie takich tekstów) włącza do grupy „inne typy tekstów” („andere Textsorten” - Snell-Hornby 1999: 273-275).

Taka propozycja wyraźnie świadczy o problemie, jaki stwarza teoretykom przekładu tłumaczenie filmowe i zarazem audiowizualne. Przekład filmowy nie wpisuje się w koncepcje dotychczasowych typologii, wymyka się ustalonym wcześniej kryteriom klasyfikacyjnym. Wewnętrznie rozczłonkowany, wskutek zastosowania niejednolitych kryteriów, wykracza poza granice jednorodnej typologii. Mimo zaprezentowanych trudności ten typ przekładu można postrzegać jako odrębny, stanowiący integralną całość z bogatym inwentarzem niejednorodnych technik przekładu wyróżnionych na podstawie wielokanałowości przepływu informacji oraz typowej dla niego cechy wielosemiotyczności (polisystemowości). Umiejscowienie przekładu audiowizualnego i zarazem filmowego w spójnym systemie klasyfikacyjnym wymaga ustalenia jednolitego kryterium. Odwołując się do podstawy nominacji rozpatrywanego tu typu tłumaczenia, a w szczególności nadrzędnego w stosunku do tłumaczenia filmowego tłumaczenia audiowizualnego, można zaproponować klasyfikację, która opiera się na sposobie doboru i wykorzystania medium jako zorganizowanego kanału komunikacyjnego przekazu informacji. Proponowana typologia tekstów (tekstu w znaczeniu szerokim, jako dowolnej formy komunikacji międzyludzkiej), a w konsekwencji i typów tłumaczenia w oparciu o wyróżnione powyżej kryterium prezentuje się następująco: 
1) teksty wizualne:

a) teksty werbalne (np. klasyczne teksty pisane),

b) teksty ikoniczne, niewerbalne (np. plakaty, filmy nieme),

c) teksty werbalno-ikoniczne (np. komiksy);

2) teksty audialne (audycje radiowe, utwory nagrane na płytach);

3) teksty audiowizualne (filmy, programy telewizyjne, publicystyczne, dokumentalne, gry wideo itp.).

Poszczególne techniki stosowane w tłumaczeniu ostatniego typu mogą służyć jako konkretne realizacje innych typów tłumaczenia, o których pisał m.in. Roman Jakobson. Propozycja nowego kryterium klasyfikacyjnego pozwoli wyprowadzić przekład filmowy z pozycji peryferyjnej, z grupy „odrębnych typów tłumaczenia”, zaproponowanej przez wspomnianą M. Snell-Hornby. Kryterium kanału przekazu informacji, mimo że jest jednym z podstawowych elementów komunikacji językowej (zaproponowanej zresztą przez Romana Jakobsona), w epoce postępu technologicznego i rozwoju nowych mediów, a w rezultacie przewartościowania zmiany preferencji w sposobie odbioru treści (od tekstu pisanego ku obrazowi) nabiera szczególnego znaczenia.

Próby lokalizacji przekładu filmowego są istotne w kontekście interdyskursywności, czyli w tym przypadku oddziaływania teorii na praktykę przekładu. Zwrócenie się ku odmiennym mediom przekazu informacji implikuje potrzebę modyfikacji na potrzeby przekładu filmowego i audiowizualnego w ogóle klasyfikacji m.in. transformacji tłumaczeniowych. Interakcyjny charakter treści audialnych i wizualnych wpływa na konstytuowanie się odmiennych niż w przypadku innych typów tłumaczeń przyczyn zastosowanych przez tłumaczy strategii i/lub procedur translatorskich.

\section{Literatura}

Bogucki, Ł., 2004, A Relevance Framework for Constraints on Cinema Subtitling, Łódź.

Garcarz, M., 2007, Przekład slangu w filmie. Telewizyjne przekłady filmów amerykańskich na język polski, Kraków.

Goc, M., 2013, „Zastosowanie opisowych badań nad przekładem do analizy tłumaczenia audiowizualnego", [w:] Przekład - teorie, terminy, terminologia. Język a komunikacja 30, M. Piotrowska, J. Dybiec-Gajec (red.), Kraków, s. 37-48.

Gouadec, D., 2007, Translation as a profession, Amsterdam-Philadelphia. 
Ekman, P., Friesen, W.V., 1969, „The repertoire of nonverbal behavior: Categories, origins, usage, and coding", [w:] Semiotica, nr 1, 69-76.

Hopfinger, M., 1997, Kultura audiowizualna u progu XXI wieku, Warszawa.

Hopfinger, M., 1974, Adaptacje filmowe utworów literackich. Problemy teorii $i$ interpretacji, Wrocław.

Pieńkos, J., 2003, Podstawy przekładoznawstwa. Od teorii do praktyki, Kraków.

Snell-Hornby, M., 1988, Translation Studies. An Integrated Approach, Amsterdam-Philadelphia.

Snell-Hornby, M., 1999, Handbuch Translation, Tübingen.

Szarkowska, A., 2008, „Przekład audiowizualny w Polsce - perspektywy i wyzwania", [w:] Przekładaniec, nr 20.

Tomaszkiewicz T., 2006, Przekład audiowizualny, Warszawa.

\section{The place of film translation in translation studies}

\section{Summary}

Contemporary audiovisual culture has contributed to a significantly increased interest in film production and film translations. Apart from practical interests, currently researchers focus even more attention on theoretical aspects of this type of translation. In different typologies of translation to date, film translation has frequently been ignored or treated marginally as a completely distinct type of translation. Meanwhile, the mass nature of the reception of audiovisual materials and the diversity of translation techniques used in film translation prompt a careful analysis of the place of film translation in the general typology of translation. The paper provides an overview of the existing typologies of film translation. At the same time it introduces a new typology, taking into account the type of information medium. On the basis of this criterion, the following types of texts and, at the same time, of translation, have been distinguished: visual (verbal, iconic, verbal-iconic), 2) audio, 3) audio-visual.

Keywords: audiovisual translation, translation techniques, translation typologies

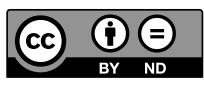

